\title{
Avaliação da resistência mecânica de pisos intertravados de concreto sustentáveis (PICS)
}

\author{
Evaluation of mechanical strength \\ of sustainable concrete paving \\ blocks (SCPB)
}

\author{
${ }^{1}$ Faculdade de Tecnologia, Universidade Estadual de Campinas, Rua Paschoal Marmo, 1888 - CEP: 13484-332, Jardim \\ Nova Itália, Limeira, SP \\ e-mail: fabiana.silva@pos.ft.unicamp.br; viviane_visnardi@yahoo.com.br; gachet@ft.unicamp.br; \\ rosacclintz@ft.unicamp.br
}

\begin{abstract}
RESUMO
O pneu inservível é um material de difícil degradação, seu acúmulo ou descarte inadequado causam graves impactos ao meio ambiente. Pneus empilhados ficam sujeitos à ocorrência de incêndios, devido a capacidade térmica que possuem, além de serem ambientes propícios para proliferação de vetores transmissores de doenças. A utilização de resíduos de borracha de pneus na produção de peças de concreto para pavimentação tem sido uma alternativa viável para destinação ambientalmente adequada destes resíduos e para redução do consumo de recursos naturais, contribuindo para sustentabilidade da construção civil. Este trabalho avalia o comportamento do concreto com adição de resíduo de borracha de pneus na produção de peças de concreto para pavimentação, onde o agregado miúdo é substituído em massa pelo resíduo de borracha nas proporções de $2.5,5.0,7.5,10,20$ e $50 \%$. Na produção dos concretos foram empregados os seguintes materiais: cimento Portland, agregados miúdos e graúdos, resíduos de borracha e aditivo superplastificante. Foram realizados ensaios de resistência à compressão em pisos intertravados aos 07 e aos 28 dias. A análise gráfica foi realizada a partir dos valores de resistência e teor de borracha, e os resultados mostraram que para um determinado intervalo de porcentagem de substituição do agregado miúdo por resíduo de borracha, houve uma melhora na resistência à compressão dos pisos intertravados, e para até $10 \%$ de substituição da areia natural pelo resíduo de borracha de pneus, é possível empregar este concreto na produção de pisos de concreto para tráfego pesado, segundo as recomendações da norma brasileira.
\end{abstract}

Palavras-chave: Materiais alternativos, Materiais de construção, Pisos intertravados com borracha.

\begin{abstract}
The waste tire is a material of difficult degradation, its inadequate accumulation or disposal cause serious environmental impacts. Stacked tires are subject to fires due to thermal capacity which have, besides being prone environments for proliferation of vectors transmitting diseases. The use of tire rubber waste in the production of paving blocks has been a viable alternative to environmentally proper disposal of this waste and to reduce the consumption of natural resources, contributing to sustainable construction. This work evaluates the behavior of the concrete with addition of tire rubber waste in the production of paving blocks. The fine aggregate was substituted by rubber waste in proportions of $2.5,5.0,7.5,10,20$ and 50\%. Portland cement, fine aggregate, coarse aggregate, rubber waste and superplastic additive were used in the concrete. Compression strength tests were performed in interlocking floor parts at 7 and 28 days. The graphical analysis was using values of resistance and rubber content, and the results showed that for a given range of proportion of substitution of fine aggregate by rubber waste, there was an improvement in the compression strength of concrete paving blocks, and with substitution of up to $10 \%$ of sand by rubber waste is possible to use this concrete to produce interlocking floor for heavy traffic, according to the recommendations of the Brazilian standard.
\end{abstract}

Keywords: Alternative materials, Construction materials, paver interlocked with rubber. 


\section{INTRODUÇÃO}

No Brasil, após a aprovação da Resolução CONAMA (Conselho Nacional do Meio Ambiente) nº 258/1999 [1] a reciclagem de pneus inservíveis teve um avanço, pois as empresas fabricantes e importadoras de pneus ficaram obrigadas a coletar e dar destinação ambientalmente adequada a eles. Atualmente está em vigor a

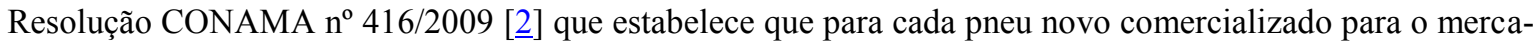
do de reposição, deverá ser destinado adequadamente um pneu inservível.

A destinação adequada são os procedimentos em que os pneus são descaracterizados de sua forma inicial, e que seus elementos constituintes são reaproveitados, reciclados ou processados por outras técnicas admitidas pelos órgãos ambientais competentes. Muitos pesquisadores têm estudado alternativas para a destinação adequada do resíduo de pneu, e o uso desse resíduo como agregado no concreto para a produção de peças de concreto para pavimentação tem se mostrado viável (SILVA et al. [3], FIORITI et al. [4], ROMUALDO et al. [5]).

O fator limitante da adição de borracha como agregado no concreto, tem sido a redução da resistência à compressão. No entanto, tem se observado ganhos de outras propriedades importantes no concreto, como aumento na flexibilidade e na capacidade de absorção de energia (FIORITI et al. [4], ROMUALDO et al. [5], SHEN et al. [6]).

Segundo SHEN et al. [6], existe um nível ótimo de substituição de agregado natural por resíduo de borracha de pneus, e quando este valor não é atingido os agregados de borracha não ficam distribuídos uniformemente no concreto e a resistência à compressão é reduzida, porque a borracha tem baixo módulo de elasticidade e isso colabora com a existência de alguns pontos fracos no concreto, de modo que a concentração de tensões ocorre em torno das partículas de borracha. Quando o teor de borracha é alto o suficiente para se distribuir uniformemente por toda a matriz, a força de carregamento também se distribui uniformemente o que leva ao aumento da resistência, e quando o valor de substituição for maior que o nível ótimo, a fragilidade do agregado de borracha torna a estrutura do concreto mais porosa e mais fraca e a resistência diminui novamente.

YUNG et al. [7], analisaram a substituição do agregado miúdo do concreto por resíduo de borracha de pneus nas proporções de 5, 10, 15 e $20 \%$ em volume, e utilizaram duas frações granulométricas de resíduo de borracha, o material retido na peneira $\mathrm{n}^{\circ} 30(0,6 \mathrm{~mm})$ e $\mathrm{n}^{\circ} 50(0,3 \mathrm{~mm})$, verificaram que quando foi adicionado $5 \%$ de pó de borracha da fração retida na peneira $\mathrm{n}^{\circ} 50$, houve um aumento de $10 \%$ na resistência à compressão.

NACIF et al. [8] chegaram à conclusão que o desempenho de compósitos de cimento com adição de borracha é afetado não só pela quantidade de borracha, mas também pelo tamanho das partículas. A borracha de tamanho menor resulta em menor densidade e porosidade aparente e maior resistência à compressão.

As pesquisas mostram que a substituição do agregado natural por resíduo de pneus no concreto, diminui a resistência à compressão, porém em proporções adequadas as partículas de borracha melhoram algumas propriedades do concreto, portanto a utilização do resíduo de pneus inservíveis como agregado no concreto, pode ser uma alternativa ambientalmente adequada colaborando com a diminuição da extração de materiais naturais e diminuindo o acúmulo desses resíduos em locais inapropriados.

A norma brasileira da ABNT NBR 9781 [9], especifica que as peças de concreto para pavimentação em tráfego leve, como tráfego de pedestres, veículos leves e comerciais de linha, devem possuir resistência à compressão aos 28 dias maior ou igual a $35 \mathrm{MPa}$. Em tráfego pesado, como tráfego de veículos especiais e solicitações capazes de produzir efeitos de abrasão acentuados, devem possuir resistência à compressão maior ou igual a $50 \mathrm{MPa}$.

Neste trabalho foi estudado o emprego do resíduo de pneus como agregado miúdo na produção de concreto para fabricação de pisos intertravados, e foi analisada a interferência na resistência à compressão das peças através de uma análise estatística do emprego de diferentes teores de substituição da areia pelo resíduo de borracha de pneus.

\section{MATERIAIS E MÉTODOS}

Nesta pesquisa foram produzidos pisos intertravados de concreto, os quais foram submetidos a ensaios de compressão axial. No processo de moldagem das misturas de concreto foram empregados os seguintes materiais: cimento Portland do tipo CPV-ARI (alta resistência inicial), agregado miúdo de origem quartzosa, agregado graúdo de origem basáltica, resíduos de borracha provenientes do processo de recauchutagem de pneus e aditivo do tipo superplastificante. 


\subsection{Ensaios para a caracterização física dos agregados}

A determinação da massa específica e unitária do agregado miúdo foi realizada conforme as especificações da ABNT NBR NM 52 [10] e ABNT NBR NM 45 [11], a determinação da massa específica e unitária do agregado graúdo foi realizada conforme a ABNT NBR NM 53 [12] e ABNT NBR NM 45 [11] e o ensaio para a determinação da granulometria dos agregados seguiu a ABNT NBR NM 248 [13]. A classificação dos agregados foi realizada conforme as especificações da ABNT NBR 7211 [14]. Os resultados obtidos nos ensaios de caracterização física dos agregados estão apresentados na Tabela 1.

Tabela 1: Caracterização física dos agregados

\begin{tabular}{l|c|c|c|c}
\hline \multicolumn{1}{c|}{ MATERIAL } & $\begin{array}{c}\text { MASSA } \\
\text { ESPECÍFICA } \\
\mathbf{( k g / l )}\end{array}$ & $\begin{array}{c}\text { MASSA UNITÁRIA } \\
\mathbf{( k g / l )}\end{array}$ & $\begin{array}{c}\text { DIMENSÃO MÁXIMA } \\
\text { CARACTERÍSTICA } \\
\mathbf{( m m})\end{array}$ & $\begin{array}{c}\text { MÓDULO DE } \\
\text { FINURA }\end{array}$ \\
\hline $\begin{array}{l}\text { Agregado miúdo natural } \\
\text { (areia) }\end{array}$ & 2,63 & 1,57 & 2,40 & 1,60 \\
\hline $\begin{array}{l}\text { Agregado miúdo artificial } \\
\text { (pó de pedra) }\end{array}$ & 2,76 & 1,56 & 4,80 & 3,07 \\
\hline $\begin{array}{l}\text { Agregado graúdo } \\
\text { (brita 0) }\end{array}$ & 2,96 & 1,50 & 9,50 & 5,36 \\
\hline Resíduo de borracha & 1,14 & 0,35 & 4,80 & 3,49 \\
\hline
\end{tabular}

\subsection{Dosagem dos concretos}

A dosagem utilizada nesta pesquisa foi baseada nos estudos de SILVA et al. [3]. Sete dosagens foram analisadas, sendo a mistura de referência $\left(\mathrm{C}_{0}\right)$ de traço em massa 1:0,77:2,33:1,11:0,43 (cimento: areia: pó de pedra: brita 0: água). Nas demais misturas, parte da areia foi substituída pelo resíduo de borracha nas seguintes porcentagens em massa: 2,5\% $\left(\mathrm{C}_{1}\right), 5,0 \%\left(\mathrm{C}_{2}\right), 7,5 \%\left(\mathrm{C}_{3}\right), 10 \%\left(\mathrm{C}_{4}\right), 20 \%\left(\mathrm{C}_{5}\right)$ e $50 \%\left(\mathrm{C}_{6}\right)$.

\subsection{Moldagem dos corpos de prova}

Na produção das misturas de concreto foi utilizada betoneira de eixo inclinado com capacidade de 55 litros e a colocação dos materiais na betoneira seguiu a ordem: agregado graúdo, água, cimento, aditivo superplastificante, areia, borracha e pó de pedra.

Após a execução de cada mistura de concreto realizou-se o ensaio para a determinação das consistências dos concretos, conforme a norma ABNT NBR NM 67 [15], cujos resultados estão apresentados na Tabela 2. Para a determinação da resistência à compressão simples segundo a ABNT NBR 9781 [9], foram moldadas peças de pisos intertravados de dimensões 200x100x60(mm).

$\mathrm{O}$ adensamento das peças de piso intertravado foi realizado em uma mesa vibratória, mantendo sempre o controle de tempo de vibração igual para todas as peças e misturas.

Tabela 2: Determinação das consistências dos concretos pelo abatimento do tronco de cone

\begin{tabular}{c|c}
\hline MISTURA & $\begin{array}{c}\text { ÍNDICE DE CONSISTÊNCIA } \\
(\mathbf{m m})\end{array}$ \\
\hline $\mathrm{C}_{0}$ & 215 \\
\hline $\mathrm{C}_{1}$ & 215 \\
\hline $\mathrm{C}_{2}$ & 165 \\
\hline $\mathrm{C}_{3}$ & 55 \\
\hline $\mathrm{C}_{4}$ & 95 \\
\hline $\mathrm{C}_{5}$ & 80 \\
\hline $\mathrm{C}_{6}$ & 125 \\
\hline
\end{tabular}




\section{RESULTADOS}

\subsection{Determinação da resistência à compressão dos pisos intertravados}

As peças de pisos intertravados foram capeadas com mistura de enxofre e caulim para o ensaio de resistência à compressão simples (conforme ABNT NBR 9781 [9]), e mantidas submersas em câmara úmida até a data do ensaio, realizado aos 7 e aos 28 dias de idade, em uma prensa universal de ensaios de capacidade de 120 toneladas. Na Tabela 3 e na Figura 1 estão apresentados os valores de resistência característica estimada à compressão $\left(f_{\text {pk,est }}\right)$ das peças de pisos intertravados aos 7 e aos 28 dias, calculados segundo ABNT NBR 9781 [9], onde: admite-se que as resistências à compressão obedeçam à distribuição normal, sendo o valor característico estimado pela equação (1):

$$
f_{p k, e s t}=f_{p}-t \times s
$$

Sendo:

$$
s=\sqrt{\frac{\sum\left(f_{p}-f_{p i}\right)^{2}}{n-1}}
$$

Onde:

$f_{p}$ é a resistência média das peças, expressa em MPa;

$f_{p i}$ é a resistência individual das peças, expressa em MPa;

$f_{p k, e s t}$ é a resistência característica estimada à compressão, expressa em $\mathrm{MPa}$;

$n$ é o número de peças da amostra;

$s$ é o desvio-padrão da amostra, expresso em MPa;

$t$ é o coeficiente de Student, em função do tamanha da amostra.

As análises dos resultados da resistência característica estimada à compressão para os pisos intertravados contendo resíduo de borracha em relação ao concreto sem resíduo de borracha estão apresentadas na Tabela 4.

Para obter maior uniformidade, foi retirada uma observação de cada amostra, utilizando o seguinte critério: retirou-se a observação que divergia do valor da média da amostra por um valor igual ou superior a 1,3 desvio-padrão do grupo. Como inicialmente cada grupo possuía sete amostras, cada grupo ficou com seis observações, porém mais uniformes.

Tabela 3: Resultados dos ensaios de resistência característica estimada à compressão simples dos pisos aos 7 e 28 dias

\begin{tabular}{c|c|c}
\hline $\begin{array}{c}\text { IDENTIFICAÇÃO DOS } \\
\text { PISOS }\end{array}$ & $\begin{array}{c}\text { Resistência } \\
\text { característica } \\
\text { estimada à } \\
\text { compressão } \\
\left(\mathbf{f}_{\mathrm{pk}, \text { st }} \text { (MPa) }\right. \\
\mathbf{7} \text { dias }\end{array}$ & $\begin{array}{c}\text { Resistência } \\
\text { característica } \\
\text { estimada à } \\
\text { compressão } \\
\left(\mathbf{f}_{\text {pk,est) }} \text { (MPa) }\right. \\
\mathbf{2 8} \text { dias }\end{array}$ \\
\hline $\mathrm{C}_{0}$ & 45,3 & 60,4 \\
\hline $\mathrm{C}_{1}$ & 49,2 & 68,3 \\
\hline $\mathrm{C}_{2}$ & 63,4 & 68,6 \\
\hline $\mathrm{C}_{3}$ & 57,7 & 65,2 \\
\hline $\mathrm{C}_{4}$ & 53,6 & 69,2 \\
\hline $\mathrm{C}_{5}$ & 41,7 & 55,3 \\
\hline $\mathrm{C}_{6}$ & 38,5 & 42,2 \\
\hline
\end{tabular}




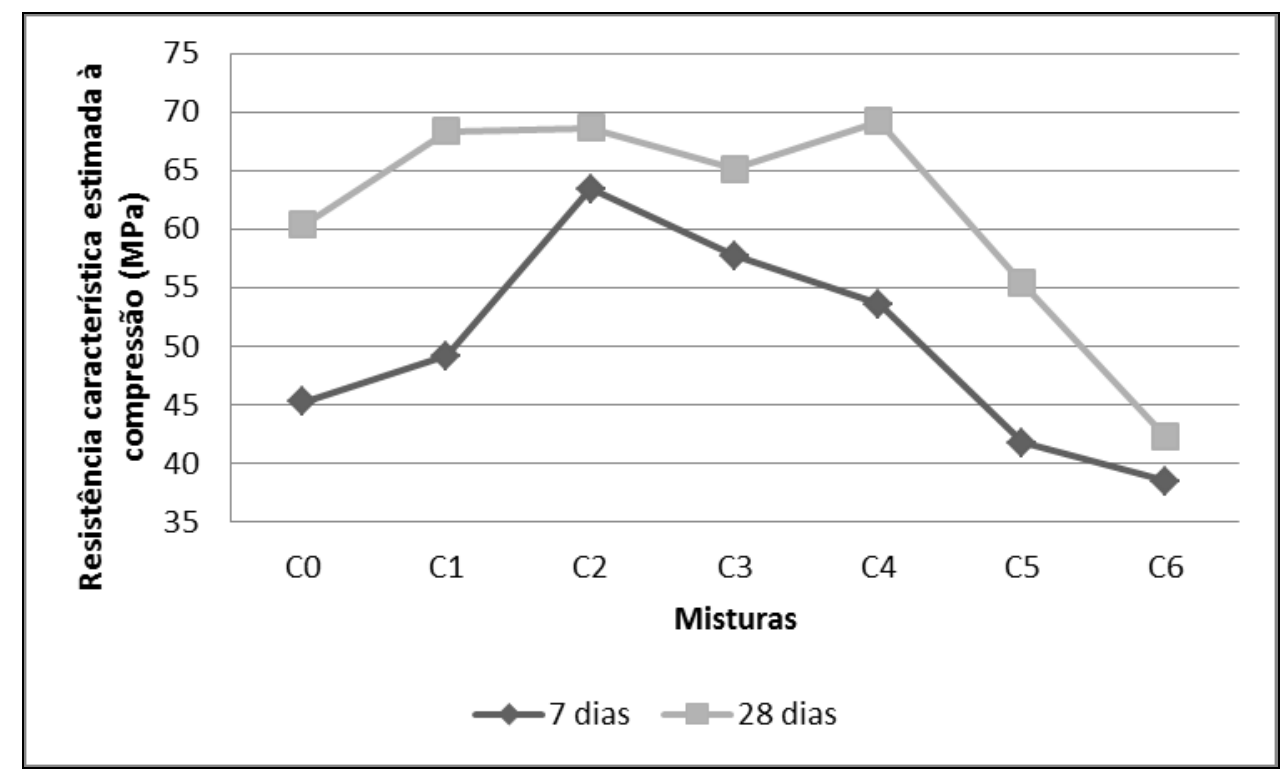

Figura 1: Resistência característica estimada à compressão simples $\left(f_{\mathrm{pk}, \mathrm{est}}\right)$ dos pisos intertravados aos 7 e 28 dias.

Tabela 4: Análise da resistência característica estimada à compressão simples dos pisos aos 7 e 28 dias

\begin{tabular}{c|c|c}
\hline \multirow{2}{*}{ MISTURA } & \multicolumn{2}{|c}{$\begin{array}{c}\text { COMPARAÇÃO EM RELAC̃O AO CONCRETO SEM RESIDUO DE } \\
\text { BORRACHA }\end{array}$} \\
\cline { 2 - 3 } & $\mathbf{7}$ DIAS & 28 DIAS \\
\hline $\mathrm{C}_{1}$ & $+8,7 \%$ (a) & $+13,2 \%$ (a) \\
\hline $\mathrm{C}_{2}$ & $+40,1 \%(\mathrm{a})$ & $+13,7 \%$ (a) \\
\hline $\mathrm{C}_{3}$ & $+25,5 \%(\mathrm{a})$ & $+7,9 \%$ (a) \\
\hline $\mathrm{C}_{4}$ & $+18,4 \%$ (a) & $-8,3 \%$ (b) \\
\hline $\mathrm{C}_{5}$ & $-7,7 \%(\mathrm{~b})$ & $-30,0 \%$ (b) \\
\hline $\mathrm{C}_{6}$ & $-15,0 \%(\mathrm{~b})$ & (a) \\
\hline
\end{tabular}

(a) Porcentagem de acréscimo em relação ao concreto sem borracha

(b) Porcentagem de decréscimo em relação ao concreto sem borracha

Foi realizada uma análise estatística dos resultados individuais de resistência à compressão das peças de pisos intertravados, utilizando a Estatística Descritiva para a análise dos resultados dentro de cada grupo conforme apresentado nas Tabelas 5 e 6 . Neste caso, foram considerados os valores individuais de resistência à compressão de cada peça de piso intertravado para o cálculo da média, desvio padrão, variância e coeficiente de variação.

Tabela 5: Estatística Descritiva da resistência à compressão dos pisos intertravados aos 7 dias

\begin{tabular}{c|c|c|c|c|c|c|c}
\hline GRUPO & C0 & C1 & C2 & C3 & C4 & C5 & C6 \\
\hline Média & 48,93 & 55,38 & 65,51 & 63,95 & 61,99 & 46,81 & 41,59 \\
\hline Desvio Padrão & 2,11 & 3,05 & 2,56 & 4,91 & 6,73 & 5,50 & 1,65 \\
\hline Variância & 4,44 & 9,31 & 6,58 & 24,11 & 45,28 & 30,29 & 2,71 \\
\hline Coeficiente de Variação & 0,04 & 0,06 & 0,04 & 0,08 & 0,11 & 0,12 & 0,04 \\
\hline
\end{tabular}


Tabela 6: Estatística Descritiva da resistência à compressão dos pisos intertravados aos 28 dias

\begin{tabular}{c|c|c|c|c|c|c|c}
\hline GRUPO & C0 & C1 & C3 & C3 & C4 & C5 & C6 \\
\hline Média & 69,29 & 75,35 & 71,85 & 71,71 & 75,42 & 59,70 & 46,89 \\
\hline Desvio Padrão & 5,41 & 3,99 & 3,49 & 7,12 & 2,09 & 2,86 & 5,05 \\
\hline Variância & 29,26 & 15,90 & 12,17 & 50,76 & 4,38 & 8,17 & 25,52 \\
\hline Coeficiente de Variação & 0,08 & 0,05 & 0,05 & 0,10 & 0,03 & 0,05 & 0,11 \\
\hline
\end{tabular}

Nas Tabelas 5 e 6 estão apresentados os valores das médias, desvio padrão, variância e coeficiente de variação para cada grupo de misturas e peças ensaiadas aos 7 e 28 dias de idade. Analisando-se os valores dos coeficientes de variação, que são uma medida de dispersão dos resultados dos ensaios, observam-se valores baixos, variando de 0,04 a 0,12 para os resultados aos 7 dias, ou seja, nas seis distribuições, em média, os desvios relativamente às médias atingem de $4 \%$ a $12 \%$ dos seus respectivos valores, e aos 28 dias variando de 0,03 a 0,11 , ou seja, nas seis distribuições, em média, os desvios relativamente às médias atingem de $3 \%$ a $11 \%$ dos seus respectivos valores, indicando homogeneidade dos valores das amostras e consequentemente consistência dos dados.

Na sequência, procedeu-se à Análise de Variância (ANOVA) para a avaliação dos resultados de resistência à compressão entre os grupos, em função do fator porcentagem de substituição do agregado miúdo pelo resíduo de borracha. A ANOVA testa se vários grupos têm a mesma média, comparando o afastamento entre as médias amostrais com a variação existente dentro dos grupos. Na Tabela 7 estão apresentados os resultado teste para a resistência à compressão dos pisos ensaiados aos 7 dias.

Tabela 7: Testes de análise de variância (ANOVA) dos pisos intertravados aos 7 dias

\begin{tabular}{c|c|c|c|c|c|c}
\hline FONTE DA VARIAÇÃO & SQ & GL & MQ & F CALC. & P-VALOR & F CRÍTICO \\
\hline Entre grupos & 3138,656 & 6 & 523,1093 & 29,83946 & $2,23 \mathrm{E}-12$ & 2,3718 \\
\hline Dentro dos grupos & 613,578 & 35 & 17,5308 & & & \\
\hline Total & 3752,233 & 41 & & & & \\
\hline
\end{tabular}

Onde: SQ indica soma quadrada, GL indica graus de liberdade, MQ indica média quadrada, $\mathrm{F}$ indica a variação (entre médias amostrais), sendo $\mathrm{F}=\mathrm{MQ}$ entre os grupos/MQ dentro dos grupos.

A hipótese nula, no teste $\mathrm{F}$ da ANOVA, afirma que todas as médias dos grupos são iguais, já a hipótese alternativa, afirma que nem todas as médias são iguais. Em uma tabela de Distribuição $F$ a 5\% $(p=0,05)$, pode-se encontrar o F crítico. Se F calculado for maior que F crítico, então rejeita-se a hipótese nula e aceita a hipótese alternativa. Outra forma de avaliar é por meio do p-valor, que é o menor nível de significância com que não se rejeitaria a hipótese nula. Em termos gerais, um p-valor pequeno significa que a probabilidade de obter um valor da estatística de teste como o observado é muito improvável, levando assim à rejeição da hipótese nula.

A análise dos resultados apresentados na Tabela 7 permite concluir que há diferença significativa entre os grupos de misturas e peças ensaiadas aos 7 dias de idade. Observa-se que F calculado é maior que $\mathrm{F}$ crítico, portanto rejeita-se a hipótese nula (que não há diferença entre os grupos) em prol da hipótese alternativa (há diferença entre os grupos) ao risco de 5\% (significância de 95\%). A análise do p-valor (2,23E-12 muito menor que 0,05 ) permite rejeitar a hipótese nula de igualdade de médias para qualquer nível de significância, uma vez que o valor é aproximadamente zero, ou seja, as médias diferem entre si com nível de significância de $95 \%$.

Outra forma de avaliação estatística é a verificação da diferença entre os grupos por meio da observação dos limites superior e inferior de cada grupo (intervalo de confiança). A Figura 2 indica que os Grupos 2 a $7\left(\mathrm{C}_{1}\right.$ a $\left.\mathrm{C}_{6}\right)$ diferem significativamente em relação ao Grupo $1\left(\mathrm{C}_{0}\right)$. 
Intervalo de confiança ( $95 \%)$

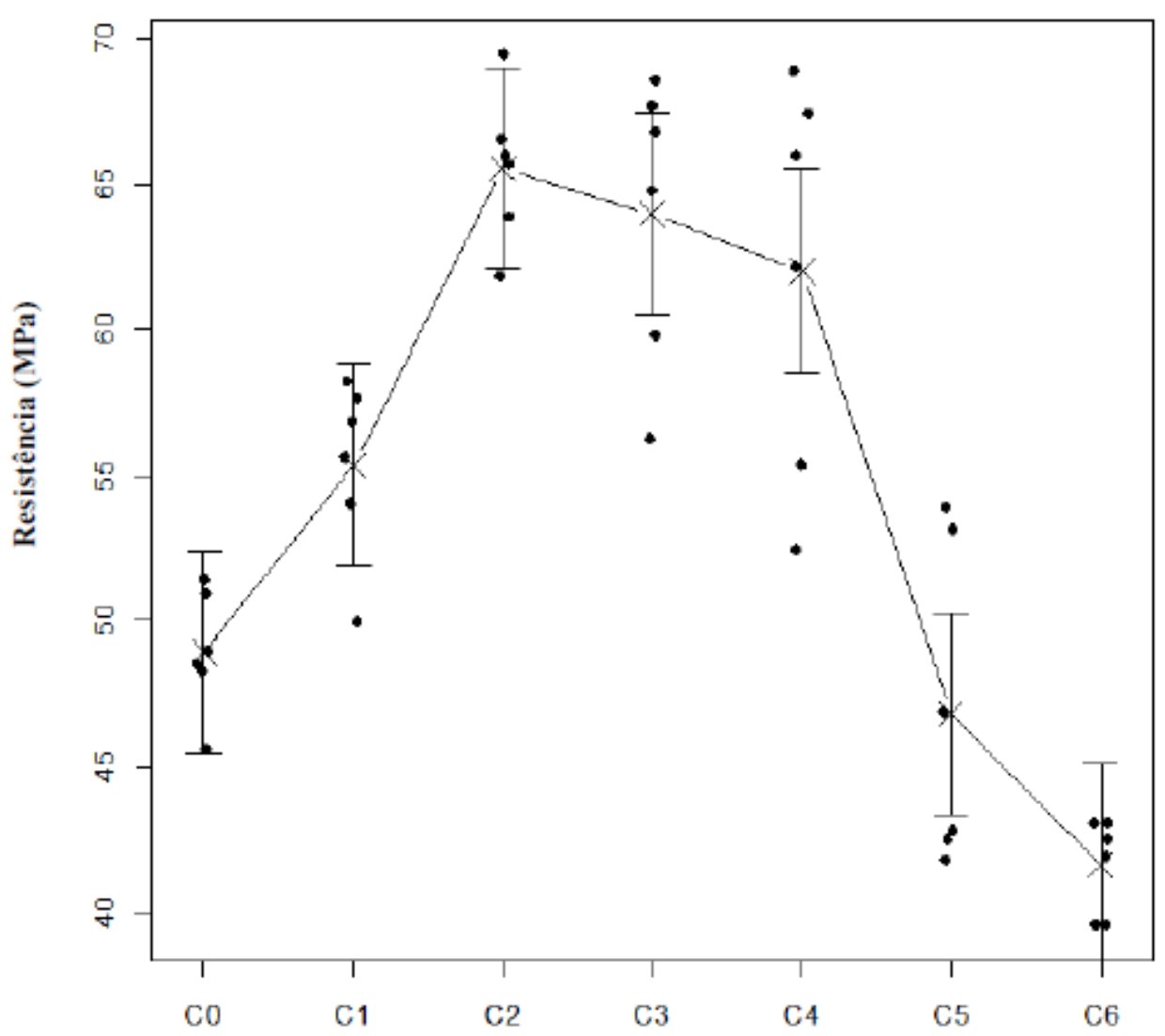

Figura 2: Intervalos de confiança para os sete grupos de pisos intertravados $\left(\mathrm{C}_{0}-\mathrm{C}_{6}\right)$, aos 7 dias

Os mesmos testes foram também efetuados para amostras com 28 dias. A Tabela 8 mostra os resultados da análise de variância (ANOVA) dos resultados do ensaio de resistência à compressão dos pisos intertravados para as diferenças entre as médias aos 28 dias.

Tabela 8: Testes de análise de variância (ANOVA) dos pisos intertravados aos 28 dias.

\begin{tabular}{l|c|c|c|c|c|c}
\hline FONTE DA VARIAÇÃO & SQ & GL & MQ & F CALC. & P-VALOR & F CRÍTICO \\
\hline Entre grupos & 3894,865 & 6 & 649,144 & 31,087 & $1,24 \mathrm{E}-12$ & 2,371781 \\
\hline Dentro dos grupos & 730,849 & 35 & 20,881 & & & \\
\hline Total & 4625,714 & 41 & & & & \\
\hline
\end{tabular}

Onde: SQ indica soma quadrada, GL indica graus de liberdade, MQ indica média quadrada, $\mathrm{F}$ indica a variação (entre médias amostrais), sendo $\mathrm{F}=\mathrm{MQ}$ entre os grupos/MQ dentro dos grupos.

A análise dos resultados apresentados na Tabela 8 permite concluir que há diferença significativa entre os grupos de misturas e peças ensaiadas aos 28 dias de idade. Observa-se que F é maior que F crítico, portanto rejeita-se a hipótese nula (que não há diferença entre os grupos) em prol da hipótese alternativa (há diferença entre os grupos) ao risco de 5\%. A análise do p-valor $(1,24 \mathrm{E}-12$ - menor que 0,05$)$ permite rejeitar a hipótese nula de igualdade de médias para qualquer nível de significância, uma vez que o valor é aproximadamente zero, ou seja, as médias diferem entre si com nível de significância de 5\%. Assim, a análise de variância ANOVA permite concluir que para qualquer nível de significância, as médias dos vários grupos não são todas iguais, o que indica que existem diferenças significativas nas médias das resistências à compressão para todas as composições de concreto utilizadas nesta pesquisa para a produção dos pisos intertravados. 
Outra forma de avaliação estatística é a verificação da diferença entre os grupos por meio da observação dos limites superior e inferior de cada grupo (intervalo de confiança). A Figura 3 indica que os Grupos 1 a $5\left(\mathrm{C}_{0}\right.$ a $\left.\mathrm{C}_{4}\right)$ diferem significativamente em relação aos Grupos 6 e $7\left(\mathrm{C}_{5}\right.$ e $\left.\mathrm{C}_{6}\right)$.

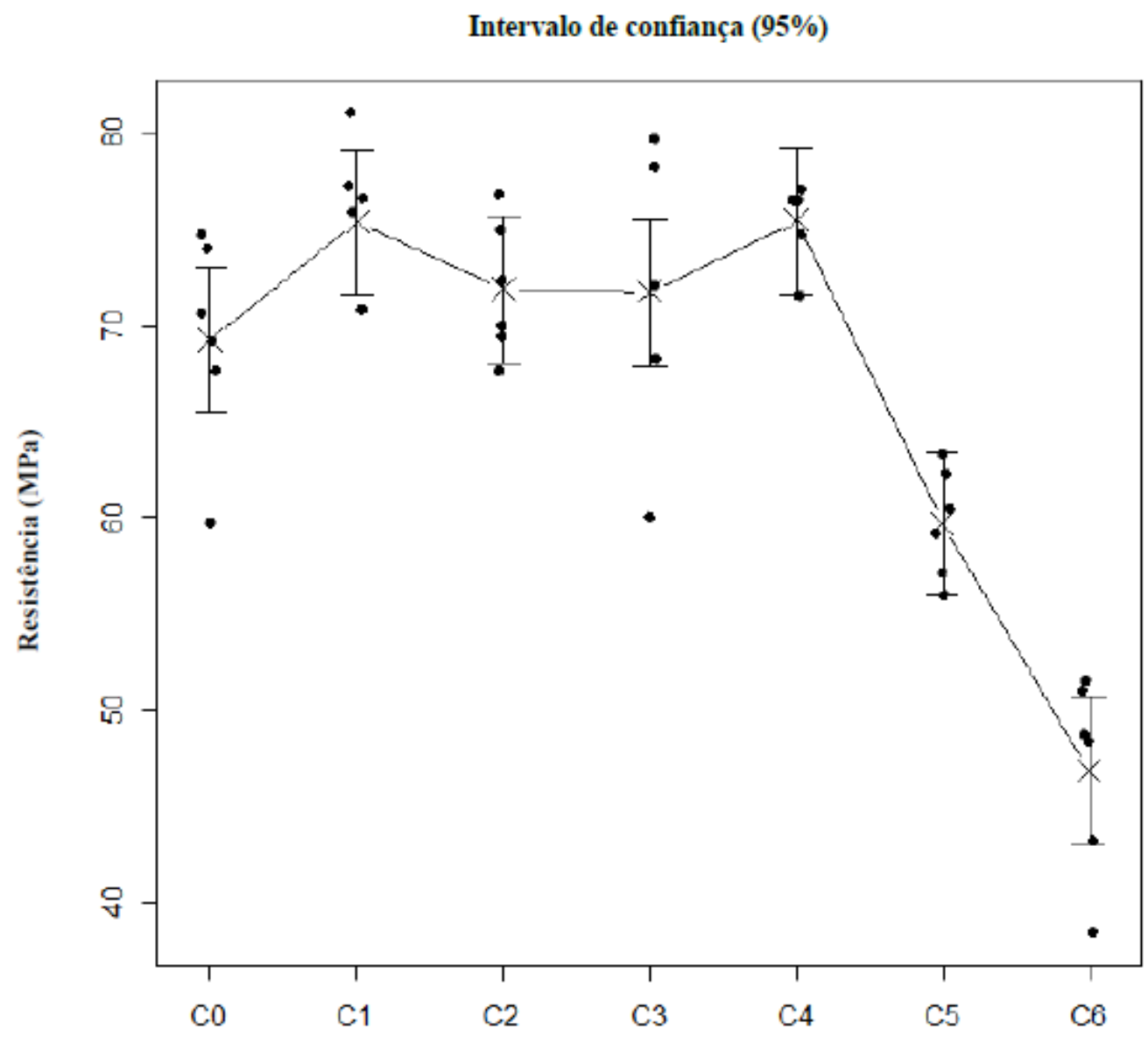

Figura 3: Intervalos de confiança para os sete grupos de pisos intertravados $\left(\mathrm{C}_{0}-\mathrm{C}_{6}\right)$, aos 28 dias

\subsection{Ensaios de absorção de água}

Foi realizado o ensaio para a determinação da capacidade de absorção de água das peças de pisos intertravados (conforme ABNT NBR 9781 [9]), aos 7 e aos 28 dias. A Tabela 9 mostra os resultados obtidos.

Tabela 9: Resultados dos ensaios de absorção de água para os pisos, aos 7 e 28 dias

\begin{tabular}{c|c|c}
\hline $\begin{array}{c}\text { IDENTIFICAÇÃO DOS } \\
\text { PISOS }\end{array}$ & $\begin{array}{c}\text { ABSORÇÃO DE ÁGUA } \\
\text { (\%) } \\
\text { 7 DIAS }\end{array}$ & $\begin{array}{c}\text { ABSORÇÃo DE ÁGUA } \\
\text { (\%) } \\
\text { 28 DIAS }\end{array}$ \\
\hline $\mathrm{C}_{0}$ & 3,23 & 3,80 \\
\hline $\mathrm{C}_{1}$ & 3,55 & 4,27 \\
\hline $\mathrm{C}_{2}$ & 3,47 & 3,05 \\
\hline $\mathrm{C}_{3}$ & 3,40 & 2,96 \\
\hline $\mathrm{C}_{4}$ & 3,33 & 2,96 \\
\hline $\mathrm{C}_{5}$ & 4,08 & 3,26 \\
\hline $\mathrm{C}_{6}$ & 4,00 & 3,56 \\
\hline
\end{tabular}


A porcentagem de absorção de água das peças de pisos intertravados, ensaiados aos 7 e aos 28 dias de idade, foram analisadas e estão apresentados na Figura 4.

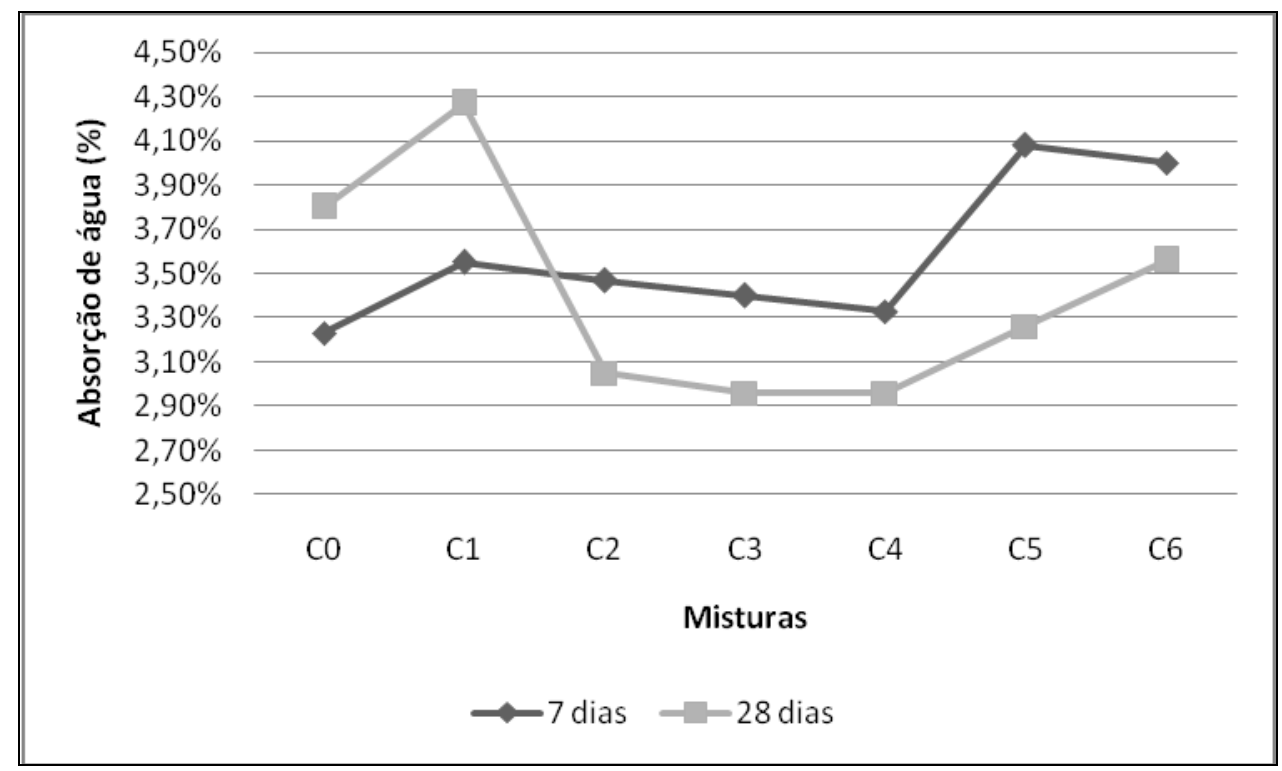

Figura 4: Capacidade de absorção de água dos pisos intertravados, aos 7 e 28 dias

\section{DISCUSSÕES}

Por meio da análise dos resultados obtidos observa-se que a substituição do agregado miúdo pelo resíduo de borracha, em determinadas porcentagens, contribui para o aumento da resistência à compressão dos pisos intertravados. Considerando-se os resultados dos ensaios de resistência à compressão dos pisos, aos 28 dias, para os traços com porcentagens de adição entre $2,5 \%$ a $10 \%$, observa-se aumento desta propriedade em relação ao traço de referência; para porcentagens acima de $20 \%$ a resistência à compressão diminui em relação ao traço de referência. Este comportamento também foi verificado no estudo de SHEN et al. [6], que concluíram que existe um nível ótimo para a substituição do agregado miúdo pelo resíduo de borracha. YUNG et al. [7] também verificou um aumento da resistência à compressão do piso em seu estudo, para substituição de $5 \%$ de pó de borracha em relação ao agregado miúdo.

O aumento na porcentagem de substituição do agregado miúdo pelo resíduo de borracha diminui a trabalhabilidade da mistura, dificultando o adensamento das peças na moldagem (conforme observado nos resultados dos índices de consistência das misturas na Tabela 2), provavelmente aumentando a porosidade das peças e conseqüentemente diminuindo a resistência à compressão das mesmas. Este decréscimo é observado na resistência à compressão simples dos pisos intertravados para as misturas $\mathrm{C}_{5}$ e $\mathrm{C}_{6}(-7,7 \% \mathrm{e}-15,0 \%$ aos 7 dias, e $-8,3 \%$ e $-30,0 \%$ aos 28 dias, respectivamente). Observa-se o aumento da porosidade dos pisos intertravados através da análise dos resultados dos ensaios de absorção de água, onde verifica-se aumento da absorção de água nos pisos proporcional ao aumento da porcentagem de substituição do agregado miúdo pelo resíduo de borracha.

A resistência à compressão simples das peças de pisos intertravados, segundo a ABNT NBR 9781 [9], deve ser maior ou igual a $35 \mathrm{MPa}$ ao serem empregados em vias destinadas ao para tráfego leve e veículos comerciais e maior ou igual a $50 \mathrm{MPa}$ para tráfego pesado e veículos especiais. De acordo com os resultados obtidos nesta pesquisa, considerando-se a resistência à compressão aos 28 dias, os pisos de traço com substituições de até $20 \%$ de areia pelo resíduo de borracha atingem resistências suficientes para atender ao tráfego de veículos especiais e as substituições de $50 \%$ atingem as resistências para tráfego leve.

A análise de variância (ANOVA) e os testes de comparações múltiplas permitem concluir que, para qualquer nível de significância, uma vez que o p-valor é aproximadamente zero, as médias dos vários grupos (para 7 e 28 dias) não são todas iguais, o que indica que existem diferenças significativas nas médias das resistências à compressão.

Estes resultados são satisfatórios e esperados, uma vez que, os resultados de cada grupo se mostraram homogêneos e entre os grupos houve diferença estaticamente significativa, indicando que a substituição de resíduo de borracha altera a resistência à compressão com o aumento da porcentagem de substituição. 


\section{CONCLUSÕES}

A partir dos resultados apresentados neste estudo, que objetiva a análise da variação da resistência à compressão simples do concreto com substituição de agregado miúdo por resíduos de borracha, conclui-se que:

$\mathrm{O}$ aumento das porcentagens de borracha altera de forma significativa os valores das resistências à compressão das peças de pisos intertravados, fato comprovado, por meio da análise de variância (ANOVA) e do teste de comparações múltiplas.

Para os de pisos intertravados de concreto com até $10 \%$ de substituições de parte do agregado miúdo pelo resíduo de borracha, observa-se um aumento da resistência à compressão simples em relação ao traço de referência, o que viabiliza a utilização dos pisos em pavimentos para tráfego pesado, pois os valores de resistência são maiores que $50 \mathrm{MPa}$, atendendo as recomendações normativas brasileiras.

Para os de pisos intertravados de concreto com porcentagens de $20 \%$ e $50 \%$ de substituições de parte do agregado miúdo pelo resíduo de borracha, nota-se que resistências à compressão são inferiores em relação ao traço de referência, sem resíduo de borracha, e que os valores de resistência para os pisos com $50 \%$ de borracha, são menores que 50MPa, porém não inferiores a $35 \mathrm{MPa}$, portanto esses pisos poderão ser indicados para aplicação em pavimentos para tráfego leve, atendendo as recomendações normativas brasileiras.

Portanto, para os traços indicados nesta pesquisa e os teores de incorporação de resíduos de borracha empregados, é possível e viável tecnicamente a utilização deste passivo ambiental na fabricação de pisos intertravados de concreto, contribuindo para minimizar os impactos ambientais.

\section{AGRADECIMENTOS}

À equipe técnica do Laboratório de Materiais de Construção da Faculdade de Tecnologia - UNICAMP, pelo auxílio na execução dos ensaios, à BASF, pela doação do aditivo superplastificante.

\section{BIBLIOGRAFIA}

[1] RESOLUÇÃO CONAMA 258 de 26 de Agosto de 1999, http://www.mma.gov.br/port/conama/res/res99/res25899.html. Acessado em janeiro de 2013.

[2] RESOLUÇÃO CONAMA 416 de 30 de Setembro de 2009, http://www.mma.gov.br/port/conama/legiabre.cfm?codlegi=616 . Acessado em janeiro de 2013.

[3] SILVA, F. M. et al., Investigation on the properties of concrete tactile paving blocks made with recycled tire rubber, Construction and Building Materials, v. 91, p. 71-79, 2015.

[4] FIORITI, C.F., INO, A., AKASAKI, J. L., Análise experimental de blocos intertravados de concreto com adição de resíduos do processo de recauchutagem de pneus, Acta Scientiarum Technology, v.32, n.3, pp. 237244, 2010.

[5] ROMUALDO, A. C. A, SANTOS, D. E., CASTRO, L. M., et al., Pneus Inservíveis como Agregados na Composição de Concreto para Calçadas de Borracha, In: $3^{\text {rd }}$ International Workshop Advances in Cleaner Production - Cleaner Production Initiatives and Challenges for a Sustainable World, São Paulo, 2011.

[6] SHEN, W., SHAN, L., ZHANG, T., et al., "Investigation on polymer - rubber aggregate modified porous concrete", Construction and Building Materials, v.38, p. 667-674, 2013.

[7] YUNG, W. H., YUNG, L. C., HUA, L. H., "A study of the durability of waste tire rubber applied to selfcompacting concrete", Construction and Building Materials, v. 41 p. 665-672, 2013.

[8] NACIF, G. L., PANZERA, T. H., STRECKER, K., "Investigations on cementitious composites based on rubber particle waste additions", Materials Research, v.16, n.2, pp. 259-268, 2012.

[9] ASSOCIAÇÃO BRASILEIRA DE NORMAS TÉCNICAS. NBR 9781 - Peças de concreto para pavimentação - Especificação e métodos de ensaio, Rio de Janeiro (2013).

[10] ASSOCIAÇÃO BRASILEIRA DE NORMAS TÉCNICAS. NBR NM 52 - Agregado miúdo - Determinação da massa específica e massa específica aparente, Rio de Janeiro, 2009.

[11] ASSOCIAÇÃO BRASILEIRA DE NORMAS TÉCNICA. NBR NM 45: Agregados - Determinação da massa unitária e do volume de vazios, Rio de Janeiro, 2006.

[12] ASSOCIAÇÃO BRASILEIRA DE NORMAS TÉCNICAS. NBR NM 53 - Agregado graúdo - Determinação da massa especifica, massa específica aparente e absorção de água, Rio de Janeiro, 2009.

[13] ASSOCIAÇÃO BRASILEIRA DE NORMAS TÉCNICAS. NBR 248 - Agregados - Determinação da composição granulométrica, Rio de Janeiro, 2003. 
[14] ASSOCIAÇÃO BRASILEIRA DE NORMAS TÉCNICAS. NBR 7211 - Agregado para concreto, Rio de Janeiro, 2009.

[15] ASSOCIAÇÃO BRASILEIRA DE NORMAS TÉCNICA. NBR NM 67: Concreto - Determinação da consistência pelo abatimento do tronco de cone, Rio de Janeiro, 1998. 